\title{
Fast tracking after repair of congenital heart defects
}

\section{Rajnish Kumar Garg ${ }^{1}$. Jameel Khan Thareen ${ }^{2} \cdot$ Akhter Mehmood $^{3} \cdot$ Christoph Johannes Fink $^{4}$ - Masakazu Nakao ${ }^{5}$. Richie Jain ${ }^{1} \cdot$ Monsy Sam ${ }^{6}$. Roberto Michele Di Donato ${ }^{5}$}

Received: 10 November 2019 /Revised: 30 December 2019 / Accepted: 2 January 2020 / Published online: 26 February 2020

(C) Indian Association of Cardiovascular-Thoracic Surgeons 2020

\begin{abstract}
Fast tracking after repair of congenital heart defects (CHD) is a process involving the reduction of perioperative period by timely admission, early extubation after surgery, short intensive care unit (ICU) stay, early mobilisation, and faster hospital discharge. It requires a coordinated multidisciplinary team involvement. In the last 2 decades, many centres have adopted the fast tracking strategy in paediatric cardiac population, safely and successfully extubating patients in the OR with reported benefits in terms of reduced morbidity and ICU/hospital stay. In this manuscript, we will review the literature available on early extubation after repair of CHD and share our experience with this approach.
\end{abstract}

Keywords Congenital heart defect $(\mathrm{CHD}) \cdot$ Fast tracking $\cdot$ Intensive care unit

\section{Introduction}

Fast tracking after repair of congenital heart defects (CHD) is a process involving the reduction of perioperative period by timely admission, early extubation after surgery, short intensive care unit (ICU) stay, early mobilisation, and faster hospital discharge. It requires a coordinated multidisciplinary team involvement. The aim is to minimise resource utilisation without compromising patient safety and comfort. Early extubation is a major component, though not a synonym, of fast tracking. It has variably been defined as the time to

Rajnish Kumar Garg

gargrajnish11@gmail.com

1 Department of Pediatric Cardiac Anesthesia, Al Jalila Children's Specialty Hospital, P.O. Box 7662, Dubai, United Arab Emirates

2 Pediatric Cardiac Surgery, Al Qassimi Hospital, Sharjah, United Arab Emirates

3 Pediatric Intensive Care, Dubai Hospital, Dubai, United Arab Emirates

4 Cardiac Intensive Care, Al Jalila Children's Specialty Hospital, Dubai, United Arab Emirates

5 Pediatric Cardiac Surgery, Al Jalila Children's Specialty Hospital, Dubai, United Arab Emirates

6 Clinical Perfusion, Al Jalila Children's Specialty Hospital, Dubai, United Arab Emirates extubation ranging from on-table extubation (OTE) up to $24 \mathrm{~h}$ after surgery. Early extubation after paediatric cardiac surgery was practiced out of necessity in the 1980 s, when reliable ventilators for paediatric patients were not available. In 1980, Barash [1] published his experience with 197 patients less than 3 years of age, including neonates, with $61 \%$ of the patients extubated in the operating room (OR). Soon afterwards, similar studies [2-4] showed that extubation in the OR could be safely pursued after open-heart surgery and was associated with lower costs due to early discharge from ICU/hospital and lesser use of resources. In the following two decades, as a result of the rapid development of surgical techniques, increasingly younger and more complex patients were accepted for repair of congenital heart defects. With time, high-dose opioid anaesthetic technique became the standard of care, as it assured better haemodynamic stability, but required prolonged mechanical ventilation after surgery. In the late 1990s, the safety and feasibility of fast tracking was shown in large adult case series. Furthermore, the added benefits of reduced costs and better patient/family satisfaction were confirmed. The feasibility of fast tracking was attributed to newer anaesthetic agents like modern inhalational agents, short-acting opioids, and muscle relaxants. The practice of high-dose opioids and post-operative mechanical ventilation extended to paediatric cardiac surgery management. In the last 2 decades, many authors have adopted the fast tracking strategy in paediatric cardiac population, safely and successfully extubating patients in the OR with reported benefits in terms 
of reduced morbidity and ICU/hospital stay [5-12]. In this manuscript, we will review the literature available on early extubation after repair of CHD and share our experience with this approach.

\section{Review of literature}

\section{Feasibility and safety}

A summary of the various studies on early extubation after paediatric cardiac surgery, with evidence of its feasibility and safety, is presented in Table 1. Various studies show that even the complex neonatal patients can be safely extubated in the OR but the decision to select the types of patients in the early extubation category mostly depends on the institutional practice, experience, and comfort of the multidisciplinary team and logistics of any specific hospital setting.

\section{Benefits}

The potential benefits of early extubation include the following: (1) reduced ventilator-associated complications like accidental extubation, pulmonary hypertensive crisis during endotracheal suctioning, infections, laryngotracheal trauma; (2) reduced sedative requirement; (3) increased patient comfort; (4) early ambulation; (5) early neurological assessment; (6) early feeding; (7) decreased ICU/hospital stay. Parent satisfaction is increased and regaining of the communication between parent, child, and hospital staff is faster. All the above combined

Table 1 Results from various studies on fast tracking after repair of congenital heart disease

\begin{tabular}{|c|c|c|c|}
\hline Author/year & Number/age of patients & Results & Comments and benefits of early extubation \\
\hline Heinle et al./1997 [2] & $56 /<90$ days & $\begin{array}{l}50 \% \text { extubated either in OR } \\
\text { or within } 3 \mathrm{~h} \text { in ICU }\end{array}$ & Shorter ICU/hospital stay, lower cost \\
\hline Vricella et al./2000 [3] & 201/0-18 years & $87 \%$ extubated in OR & Fast tracking is safe and feasible, early discharge from hospital \\
\hline Peterson et al./2000 [4] & 220 & $89 \%$ extubated in OR & $\begin{array}{l}\text { Regional anaesthesia is safe and effective in the management } \\
\text { of paediatric patients undergoing cardiac surgery }\end{array}$ \\
\hline Cray et al./2001 [5] & $\begin{array}{l}103 />6 \\
\text { months }-<18 \text { years }\end{array}$ & $\begin{array}{l}54 \% \text { extubated within } 6 \mathrm{~h} \text {, } \\
73 \% \text { within } 9 \mathrm{~h}\end{array}$ & Short ICU stay \\
\hline Neirotti et al./2002 [6] & $901 /$ & $73 \%$ extubated in OR & $\begin{array}{l}\text { Simplified post-operative care and increased patient } \\
\text { and family satisfaction, shorter hospital stay }\end{array}$ \\
\hline Kloth et al./2002 [7] & $102 />2$ months & $41 \%$ extubated in OR & $\begin{array}{l}\text { Successful early extubation of even young children is } \\
\text { possible and easily accomplished in most children } \\
\text { undergoing cardiopulmonary bypass, even with } \\
\text { complex procedures }\end{array}$ \\
\hline Davis et al./2004 [8] & $219 /<36$ months & $47 \%$ extubated in OR & $\begin{array}{l}\text { Early extubation is possible in many very young children } \\
\text { undergoing congenital heart surgery, with a low rate of } \\
\text { failed extubation }\end{array}$ \\
\hline Vida et al./2006 [9] & $100 / 0.4-30$ years & $65 \%$ extubated in OR & Decreased ICU and hospital stay, reduced costs \\
\hline Mittnacht et al./2008 [10] & $224 />1$ month $<18$ years & $79 \%$ extubated in OR & $\begin{array}{l}\text { Extubation in operating room was successful in the majority } \\
\text { of patients including infants and complex procedures }\end{array}$ \\
\hline Preisman et al./2009 [11] & $100 / 1$ month -15 years & & $\begin{array}{l}\text { Early extubation is safe and decreases ICU and hospital } \\
\text { length of stay }\end{array}$ \\
\hline Garg et al./2014 [13] & $1000 / 1$ day-18 years & $87 \%$ extubated in OR & $\begin{array}{l}\text { Extubation in operating room was successful in the majority } \\
\text { of patients including neonates and complex procedures, } \\
\text { shorter ICU stay, less use of hospital resources }\end{array}$ \\
\hline Harris et al./2014 [24] & 613/neonates-children & $\begin{array}{l}71 \% \text { extubated in OR, } 89 \% \\
\text { within } 24 \mathrm{~h}\end{array}$ & $\begin{array}{l}\text { Most children including neonates undergoing congenital heart } \\
\text { surgery can be extubated in the operating room; early } \\
\text { extubation decreases morbidity and ICU stay and hospital } \\
\text { length of stay }\end{array}$ \\
\hline Varghese et al./2017 [27] & $32 /$ neonates with d-TGA & $56 \%$ extubated in OR & Shorter ICU stay in patients extubated in OR \\
\hline $\begin{array}{l}\text { Shinkawa et al./2018 } \\
\text { [25] }\end{array}$ & 909/neonates-adults & $64.9 \%$ extubated in OR & $\begin{array}{l}\text { Immediate extubation in OR can be performed in most } \\
\text { patients and associated with lower reintubation }\end{array}$ \\
\hline Garg et al./current study & 287/neonates-children & $90.2 \%$ extubated in OR & $\begin{array}{l}\text { Most children including neonates undergoing complex congenital } \\
\text { heart surgery can be safely extubated in operating room } \\
\text { based on assessment of intraoperative course }\end{array}$ \\
\hline
\end{tabular}

$O R$ operating room, $I C U$ intensive care unit 
benefits ultimately lead to lessened personnel requirement and reduced costs [13].

\section{Factors associated with the need for mechanical ventilation after surgery for CHD}

The various patient factors deterring the physicians from pursuing early extubation, with the effect of continuing mechanical ventilation throughout the post-operative period, are as follows: younger age (especially neonates), longer cardiopulmonary bypass (CPB)/aortic cross clamp times, ventricular dysfunction requiring high dose of inotropes, pulmonary hypertension, Down's syndrome, unsatisfactory haemostasis and need for intraoperative transfusion, coagulopathy, pulmonary dysfunction impairing gas exchange, post-operative pain, hypothermia, intraoperative fluid overload, and preoperative mechanical ventilation. This hesitance towards fast tracking has persisted despite several studies having shown that neonates undergoing complex repairs can be safely extubated in the $\mathrm{OR}$, but the incidence of extubation is less as compared with that in older population. The decision to practice fast tracking in high-risk patients is taken on individual basis by the multidisciplinary team according to the comfort and experience of the team, keeping patient safety as the top priority.

\section{Our experience}

We started our on-table extubation experience in Narayana Institute of Cardiac Sciences, Bangalore, where 10-12 paediatric cardiac surgeries were performed everyday. At any one moment in time, up to 40 patients used be on mechanical ventilation in a 60-bed ICU with a variable number of patients frequently experiencing complications of prolonged ventilation, posing several challenges in terms of patient outcomes, manpower requirement, and resource consumption. A major change in practice was required which could safely reduce complications and provide better use of resources. After reviewing the literature on OTE, showing encouraging results in terms of feasibility and safety of OTE in children after cardiac surgery, we decided to adopt this practice on a routine basis. To bring about such a change, consensus was achieved among members of all the involved specialities. In a multidisciplinary team meeting, anaesthetic plan, surgical goals, perfusion strategy, modalities of intraoperative assessment, postoperative monitoring, and sedation protocols were finalised.

The detailed anaesthetic plan was already published [13]. It followed the standard-of-care procedures with the aim to limit the use of systemic opioids (fentanyl up to $5 \mu \mathrm{g} / \mathrm{kg}$ ) supplemented with the addition of caudal analgesia [14-20] as a single-shot procedure, using a mixture of morphine in a dose of $100 \mu \mathrm{g} / \mathrm{kg}$ and dexmedetomidine $1 \mu \mathrm{g} / \mathrm{kg}$ diluted to a volume of $1 \mathrm{ml} / \mathrm{kg}$, to provide both intra- and post-operative analgesia. Induction and maintenance were achieved with oxygen, inhalational agent, even during $\mathrm{CPB}$, and standard doses of muscle relaxants. Trans-oesophageal echocardiography (TEE) probe was inserted in every patient to assess surgical repair and cardiac function. Every effort was undertaken to minimise the systemic inflammatory response syndrome (SIRS) and excessive increase in body water during CPB by miniaturisation of the circuit, pre-bypass filtration, and conventional (CUF) and modified ultrafiltration (MUF), maintaining a targeted haematocrit of $27 \%$ and $30 \%$ in infants and neonates, respectively [21-23]. Meticulous monitoring of systemic venous drainage, especially of the inferior vena cava, was done by a perfusionist to prevent critical reduction of pump flow and unwanted volume additions. Surgically, the goal was to ensure good surgical repair (i.e. without residual correctable lesions) and accurate haemostasis. At the end of surgery, TEE assessment was carried out to assess surgical repair. The identified residual correctable lesions were addressed in the same surgical session with no hesitation to undertake additional periods of $\mathrm{CPB}$ and aortic crossclamping.

At the end of the operation, OTE was pursued in all patients, provided the absence of any of the following conditions: (1) the sternum left open; (2) an arterial oxygen tension $\left(\mathrm{PaO}_{2}\right)$ less than $80 \mathrm{mmHg}$ in patients who received total correction and less than $55 \mathrm{mmHg}$ in those who underwent palliative procedure, in both cases with an inspired oxygen fraction of 0.50 and arterial carbon dioxide tension $\left(\mathrm{PaCO}_{2}\right)$ more than $55 \mathrm{mmHg}$; (3) an unsatisfactory haemostasis requiring transfusion of packed red blood cells more than $20 \%$ of blood volume during the post-bypass period; (4) the presence of haemodynamic instability requiring more than $7.5 \mu \mathrm{g} / \mathrm{kg} /$ min of dobutamine and more than $0.075 \mu \mathrm{g} / \mathrm{kg} / \mathrm{min}$ of adrenaline (equivalent to an inotrope score of more than 15); (5) any other surgical concern due to patient factors, such as a particularly complex native morphology, for which the surgeon felt the need for further observation in the intensive care unit [13].

In the absence of the abovementioned factors, neuromuscular blockade was reversed and, after ensuring adequate ventilator effort and gas exchange, endotracheal tube was removed. Oxygen was administered via a nasal cannula. If a patient was agitated, intravenous midazolam $0.1 \mathrm{mg} / \mathrm{kg}$ was administered.

Patients raising concerns like bleeding, pulmonary dysfunction, and/or cardiac dysfunction were shifted to ICU on ventilator and placed on a regime of sedation with dexmedetomidine $(0.5 \mu \mathrm{g} / \mathrm{kg} / \mathrm{h})$ and fentanyl $(1 \mu \mathrm{g} / \mathrm{kg} / \mathrm{h})$ and occasionally paralysis. These patients were then extubated by the intensivists according to standard extubation criteria.

Post-operative patients were monitored according to standard criteria and sedation/analgesia with dexmedetomidine and fentanyl was titrated for each patient. In the ICU, every patient underwent transthoracic echocardiography as a 
baseline for assessment of surgical repair, cardiac function, diaphragm movement, and pulmonary artery pressure (especially in the cases with pulmonary artery hypertension). Echocardiography was repeated within $6-8 \mathrm{~h}$ for reassessment. Each patient was managed subsequently according to standardised ICU protocols.

\section{Results}

In the initial series of 1000 consecutive patients, we were able to extubate $87 \%$ of the patients ( $n=871 / 1000)$, including $40 \%$ of the neonates $(n=8 / 20), 81 \%$ of the infants $(n=264 / 327)$, and $92 \%$ of the children $(n=599 / 653)$. Hospital mortality $(1 \%)$ among the extubated population and early reintubation $(5 \%)$ rates were unrelated to OTE. Duration of ICU stay decreased from $5.4 \pm 2.3$ to $2.6 \pm 1.8$ days [13].

\section{Learnings from experience and continuation of fast tracking}

Performing OTE was a major change in our clinical practice and every effort was made to accomplish it successfully. Few changes were applied in the ICU while managing these patients:

- Accepting $\mathrm{PaCO}_{2}$ levels up to 50-60 $\mathrm{mmHg}$, a common finding after caudal morphine injection, as it usually settled in $1-2 \mathrm{~h}$

- Minimal/no handling of the patients in the initial half-anhour to avoid haemodynamic instability and breath holding especially in neonates and infants

- Performing transthoracic echocardiography as early as possible to provide a baseline for cardiac status and repeating the assessment after $6 \mathrm{~h}$ or earlier in the case of any haemodynamic compromise

- Starting early feeding (after 4-6 h) as the children used to cry because of hunger, which was suspected, as there were no objective signs of pain. In fact, older children used to deny having pain and explicitly asked for food while infants used to pacify after feeding

After initial experience, we continued the same practice and extended the same approach in different hospital settings (job relocation and involvement in several charity missions) with more inspiration from different studies [24-28]. In the past 3 years, with the addition of new members, we have been able to replicate our OTE strategy with consistent results in 6 different hospitals. We are now able to extubate approximately $90 \%$ of the patients on-table with re-intubation rate as low as $1.4 \%$. With this practice and increasing confidence of each team component, we have been able to achieve OTE in several patients in whom this approach would normally be considered contraindicated according to the standard management criteria, for example high Aristotle score (including our only 2 Norwood patients) [29], low weight, long CPB and aortic cross-clamp times, and mechanical ventilation dependence prior to surgery. For example, we were able to extubate $84 \%$ of the patients with long CPB (more than $180 \mathrm{~min}$ ) (Table 2).

\section{Discussion}

Though ventilators are important tools in the armamentarium for the post-operative management of children undergoing surgery for CHD, mechanical ventilation for as short as $18 \mathrm{~h}$ leads to significant loss of cross-sectional area of diaphragmatic muscle fibres $[30,31]$. Every hour of mechanical

Table 2 Details of patients extubated on table

\begin{tabular}{|c|c|c|}
\hline Type of patients & $\begin{array}{l}\text { Number of patients } \\
\text { extubated on-table/ } \\
\text { total patients }(\%)\end{array}$ & $\begin{array}{l}\text { Reintubation/mortality } \\
\text { among extubated on- } \\
\text { table/total mortality }\end{array}$ \\
\hline $\begin{array}{l}\text { All paediatric cardiac } \\
\text { surgeries }\end{array}$ & $259 / 287(90.2 \%)$ & $4 / 2 / 11$ \\
\hline \multicolumn{3}{|l|}{ High-risk category } \\
\hline $\begin{array}{l}\text { TAPVC, age } \\
<1 \text { year, severe } \\
\text { PAH }\end{array}$ & $6 / 6(100 \%)$ & No reintubation/nil/nil \\
\hline $\begin{array}{l}\text { AVCD with Down's } \\
\text { syndrome, severe } \\
\text { PAH }\end{array}$ & $13 / 15(86.6 \%)$ & No reintubation/nil/nil \\
\hline $\begin{array}{l}\text { AVCD without } \\
\text { Down's syndrome, } \\
\text { severe PAH }\end{array}$ & $1 / 1(100)$ & No reintubation/nil/nil \\
\hline $\begin{array}{l}\text { VSD and aortic valve } \\
\text { repair }\end{array}$ & 1/1 (100\%) & No reintubation/nil/nil \\
\hline $\begin{array}{l}\text { VSD with aortic arch } \\
\text { repair }\end{array}$ & $2 / 2(100 \%)$ & No reintubation/nil/nil \\
\hline Rastelli procedure & $1 / 1(100 \%)$ & No reintubation/nil/nil \\
\hline Nikaidoh procedure & $1 / 1(100 \%)$ & No reintubation/nil/nil \\
\hline Ross procedure & $1 / 1(100 \%)$ & No reintubation/nil/nil \\
\hline Norwood procedure & $2 / 2$ & No reintubation/nil/nil \\
\hline ASO & $14 / 17(82.3 \%)$ & $\begin{array}{l}1 \text { reintubation due to } \\
\text { desaturation/nil/2 }\end{array}$ \\
\hline Damus-Kaye-Stansel & $0 / 2(0 \%)$ & Nil/nil/1 \\
\hline $\begin{array}{l}\text { Truncus arteriosus } \\
\text { repair }\end{array}$ & $1 / 2(50 \%)$ & No reintubations/nil/1 \\
\hline \multicolumn{3}{|c|}{ Patients with $\mathrm{CPB}$ duration more than $180 \mathrm{~min}$} \\
\hline Neonates & $15 / 21(71.4 \%)$ & No reintubations/nil/nil \\
\hline Infants & $32 / 36(88.8 \%)$ & $\begin{array}{l}1 \text { reintubation due to } \\
\text { desaturation/nil/nil }\end{array}$ \\
\hline Children & $21 / 24(87.5 \%)$ & No reintubations/nil/nil \\
\hline
\end{tabular}

$T A P V C$ total anomalous pulmonary venous connection, $P A H$ pulmonary artery hypertension, $A V C D$ atrioventricular canal defect, $L C O S$ low cardiac output syndrome, $V S D$ ventricular septal defect, $T O F$ tetralogy of Fallot, $A S O$ arterial switch operation, $C P B$ cardiopulmonary bypass 
ventilation increases the risk which gets compounded with the addition of sedatives.

Our persistence in performing OTE has raised many questions such as the following: Is it really necessary to go out of the comfort zone and extubate the patients in the OR when this can be easily done in the ICU in a few hours? Or, are we compromising on the patient safety especially after a major surgery with anticipated haemodynamic fluctuations? Or, are we really saving time and/or money? and many more. Although to bring a change is difficult, the enthusiasm and acceptance by the entire team for a beneficial outcome brought a significant change in our practice.

In a recent multicentre international survey [30,31], from both European and non-European countries, a majority of paediatric cardiac anaesthesiologists practice OTE, safety of OTE was perceived as excellent by $70 \%$ of the respondents, and none of them had stopped OTE for safety reasons. The practice of OTE varies among institutions, depending on physician preferences, comfort of the entire team, and other logistic considerations.

Younger age, low body weight, and complex cardiac lesions, though lead to more physiological derangement in the perioperative period, should not deter us from pursuing OTE/ early extubation approach at the outset, but every patient should be assessed individually at the end of the surgery. It has been proven by many recent studies that these factors are not limiting the physicians from doing OTE [2-11, 24-29]. Paradoxically, a baby undergoing an arterial switch operation may be suitable for OTE, whereas a patient with a simple atrial septal defect may not qualify for extubation due to a number of patient-related issues.

The other reason for rejecting OTE by many is the slow turnover time in the operation theatre and the associated additional costs, but with increasing experience and confidence, this time can be minimised significantly. We spend 5-10 min extra in the operating room whereas time as short as $2 \mathrm{~min}$ has been reported by Shinkawa et al. [25].

Proper anaesthetic plan, with the aim of avoiding use of long-acting drugs and high-dose opioids, is very critical for the practice of fast tracking. Profound analgesia without the risk of respiratory depression is of utmost importance. This was achieved in many centres by using neuraxial blockade with success in children undergoing surgery for repair of CHD. We used caudal route in all the patients, obtaining excellent analgesia in the perioperative period. Systemic narcotics carry higher risk of respiratory depression which can instead be avoided by the use of dexmedetomidine. We have administered dexmedetomidine via the caudal route intraoperatively as well as systemically in the postoperative period which helped in reducing the dose of other sedatives and narcotics. The use of dexmedetomidine is increasing with the documented evidence of reduced mortality with its use [32].
Pulmonary dysfunction, secondary to CPB and volume overload, and hypothermia are among the factors which deter anaesthesiologists from fast tracking. We were able to minimise pulmonary dysfunction by removing extra fluid with the help of CUF and MUF. Hypothermia was avoided by warm blanket, wrapping the patients with cotton pad and blowing warm air under the drapes.

Presence of residual surgical lesions and bleeding requiring significant blood transfusion are limiting factors for fast tracking. Both these factors can be, most probably, ruled out intraoperatively. Every patient should undergo TEE to assess the surgical repair, and any residual defect should be addressed in the same surgical session. We performed TEE in every patient and, if any patient required blood transfusion, due to unexplained cause, of more than $20 \%$ of patient volume, extubation was deferred as outlined in our criteria.

CPB initiates a cascade of events leading to capillary leak, interstitial oedema, and multiorgan damage which are more pronounced with increasing duration of $\mathrm{CPB}$. The effects of CPB can be minimised by technological advances like miniaturisation of the circuit and various modalities of ultrafiltration to name a few. With increasing experience and confidence of the team, we observed that even a very long duration of CPB, with or without a period of deep hypothermic circulatory arrest, does not limit the suitability of the patient for OTE, as long as the homeostasis is maintained.

Pulmonary hypertension is considered a contraindication for early extubation. Post-operative pain and, particularly, endotracheal tube suctioning are the main causes for postoperative pulmonary hypertensive crises in predisposed patients. Vida et al. concluded that pulmonary hypertension does not seem to be a contraindication for early extubation [9]. We also observed similar results and believe that a successful OTE strategy should include a multimodal approach to adequate pain control, and in the absence of an endotracheal tube, frequent suctioning of the trachea and bronchial tree is not required. Mild hypercapnia observed in the immediate postoperative period in our patients was well tolerated despite a theoretical risk to aggravate pulmonary hypertension and right ventricular dysfunction. We observed that none of the patients showed any sign of worsening right ventricular function (as assessed by serial transthoracic echocardiography), desaturation, bradycardia, or reintubation. Similar observation was made by Kloth et al. [7].

Reintubation is always a concern after early extubation, but different studies have shown that the risk of reintubation is less in the early extubated group than in those extubated late. Our reintubation rate is as low as $1.25 \%$ in the patients extubated on-table.

Factors contributing to contraindications to OTE, like inadequate gas exchange, bleeding, ventricular dysfunction requiring high inotropes, and residual lesion, have also been identified. However, these are attributed to patient- or 
surgery-related factors, contingently raising concerns about post-operative clinical stability [13].

Our initial study lacks a control group to label it as a better practice. Since the study was done in a short period of 8 months and it had historical controls, all the benefits related to resource utilisation were assumed to be related to the change in practice. Many authors have done direct cost-saving estimates [33]. The practice of OTE was implemented as a routine for all the patients according to the specified criteria.

Though fast tracking may be a necessity during charity missions or in resource-constrained setting, it has been identified as one of the goals of international quality improvement initiatives [34]. Successful fast tracking reflects a team-based approach, and it is a very reassuring experience to see a child already awake and spontaneously breathing in the immediate post-operative period, even after a complex cardiac operation. OTE patients may need much more attention in the first $1-2 \mathrm{~h}$ but post-operative complications are avoided, as well as ICU/ hospital stay is reduced. This leads to more efficient utilisation of resources [13] and possibly reduction of costs. This practice can be implemented if all the team members of perioperative care collectively plan, assess, and manage the patients [35].

\section{Conclusions}

In our experience, fast tracking in paediatric cardiac surgical patients was safe with probable clinical benefit and better use of resources. This model of management might be worthy of practice, keeping patient safety as top priority, with acceptance by all the team members to reap clinical and resource benefits.

\section{Compliance with ethical standards}

\section{Conflict of interest None.}

Ethical committee approval Not required being a review article.

Informed consent Not required being a review article.

Funding None.

Human and animal rights Not required being a review article.

\section{References}

1. Barash PG, Lescovich F, Katz JD, Talner NS, Stansel HC Jr. Early extubation following pediatric cardiothoracic operation: a viable alternative. Ann Thorac Surg. 1980;29:228-33.

2. Heinle JS, Diaz LK, Fox LS. Early extubation after cardiac operations in neonates and young infants. J Thorac Cardiovasc Surg. 1997;114:413-8.
3. Vricella LA, Dearani JA, Gundry SR, Razzouk AJ, Brauer SD, Bailey LL. Ultra fast track in elective congenital cardiac surgery. Ann Thorac Surg. 2000;69:865-71.

4. Peterson KL, DeCampli WM, Pike NA, Robbins RC, Reitz BA. A report of two hundred twenty cases of regional anesthesia in pediatric cardiac surgery. Anesth Analg. 2000;90:1014-9.

5. Cray SH, Holtby HM, Kartha VM, Cox PN, Roy WL. Early tracheal extubation after paediatric cardiac surgery: the use of propofol to supplement low-dose opioid anaesthesia. Paediatr Anaesth. 2001;11:465-71.

6. Neirotti RA, Jones D, Hackbarth R, Paxson Fosse G. Early extubation in congenital heart surgery. Heart Lung Circ. 2002;11: $157-61$.

7. Kloth RL, Baum VC. Very early extubation in children after cardiac surgery. Crit Care Med. 2002;30:787-91.

8. Davis S, Worley S, Mee RB, Harrison AM. Factors associated with early extubation after cardiac surgery in young children. Pediatr Crit Care Med. 2004;5:63-8.

9. Vida VL, Leon-Wyss J, Rojas M, et al. Pulmonary artery hypertension: is it really a contraindicating factor for early extubation in children after cardiac surgery? Ann Thorac Surg. 2006;81:1460-5.

10. Mittnacht AJC, Thanjan M, Srivastava S, et al. Extubation in the operating room after congenital heart surgery in children. J ThoracCardiovasc Surg. 2008;136:88-93.

11. Preisman S, Lembersky H, Yusim Y, et al. A randomized trial of outcomes of anesthetic management directed to very early extubation after cardiac surgery in children. J CardiothoracVasc Anesth. 2009; 23:348-357.

12. Lawrence EJ, Nguyen K, Morris SA, et al. Economic and safety implications of introducing fast tracking in congenital heart surgery. Circ Cardiovasc Qual Outcomes. 2013;6:201-7.

13. Garg R, Rao S, John C, et al. Extubation in the operating room after cardiac surgery in children: a prospective observational study with multidisciplinary coordinated approach. J Cardiothorac Vasc Anesth. 2014;28:479-87.

14. Rosen KR, Rosen DA. Caudal epidural morphine for control of pain following open heart surgery in children. Anesthesiology. 1989;70:418-21.

15. Leyvi G, Taylor DG, Reith E, Stock A, Crooke G, Wasnick JD. Caudal anesthesia in pediatric cardiac surgery: does it affect outcome? J Cardiothorac Vasc Anesth. 2005;19:734-8.

16. Rojas-Perez E, Castillo-Zamora C, Nava-Ocampo AA. A randomized trial of caudal block with bupivacaine $4 \mathrm{mg} / \mathrm{kg}-1(1.8 \mathrm{ml} / \mathrm{kg}-1)$ plus morphine $(150 \mathrm{mcg} / \mathrm{kg}-1)$ vs general anaesthesia with fentanyl for cardiac surgery. Paediatr Anaesth. 2003;13:311-7.

17. Tenenbein PK, Debrouwere R, Maguire D, et al. Thoracic epidural analgesia improves pulmonary function in patients undergoing cardiac surgery. Can J Anaesth. 2008;55:344-50.

18. Chrysostomou C, Di Filippo S, Manrique AM, et al. Use of dexmedetomidine in children after cardiac and thoracic surgery. PediatrCrit Care Med. 2006;7:126-31.

19. Easley RB, Tobias JD. Pro: dexmedetomidine should be used for infants and children undergoing cardiac surgery. J Cardiothorac Vasc Anesth. 2008;22:147-51.

20. Nasr DA, Abdelhamid HM. The efficacy of caudal dexmedetomidine on stress response and postoperative pain in pediatric cardiac surgery. Ann Card Anaesth. 2013;16:109-14.

21. Sever K, Tansel T, Basaran M, et al. The benefits of continuous ultrafiltration in pediatric cardiac surgery. Scand Cardiovasc J. 2004;38:307-11.

22. Mahmoud AB, Burhani MS, Hannef AA, Jamjoom AA, Al-Githmi IS, Baslaim GM. Effect of modified ultrafiltration on pulmonary function after cardiopulmonary bypass. Chest. 2005;128:3447-53.

23. Kameyama T, Ando F, Okamoto F, et al. The effect of modified ultrafiltration in pediatric open heart surgery. Ann Thorac Cardiovasc Surg. 2000;6:19-26. 
24. Harris KC, Holowachuk S, Pitfield S, et al. Should early extubation be the goal for children after congenital cardiac surgery? J Thorac Cardiovasc Surg. 2014;148:2642-8.

25. Shinkawa T, Tang X, Gossett JM, et al. Incidence of immediate extubation after pediatric cardiac surgery and predictors for reintubation. World J Pediatr Congenit Heart Surg. 2018; 9: 529-36.

26. Varghese J, Kutty S, Abdullah I, Hall S, Shostrom V, Hammel JM. Preoperative and intraoperative predictive factors of immediate extubation after neonatal cardiac surgery. Ann Thorac Surg. 2016;102:1588-95.

27. Varghese J, Kutty S, Moukagna KSB, Craft M, Abdullah I, Hammel JM. Five-year experience with immediate extubation after arterial switch operation for transposition of great arteries. Eur J Cardiothorac Surg. 2017;51:728-34.

28. Varghese J, Hammel JM, Ibrahimiye AN, Siecke R, Bisselou Moukagna KS, Kutty S. Outcomes related to immediate extubation after stage 1 Norwood palliation for hypoplastic left heart syndrome. J Thorac Cardiovasc Surg. 2019;157:1591-8.

29. Garg RK, Thareen JK, Ramaiah AKH, Di Donato RM. On-table extubation after Norwood operation. J Cardiothorac Vasc Anesth. 2019;33:2760-2.

30. Bichell DP. Commentary: mechanical ventilation: a toxic asset. J Thorac Cardiovasc Surg. 2019;157:1599-600.
31. Akhtar MI, Momeni M, Szekely A, Hamid M, El Tahan MR, Rex S. Multicenter international survey on the clinical practice of ultrafast track anesthesia with on table extubation in pediatric congenital cardiac surgery. J CardiothoracVasc Anesth. 2019;33:406-15.

32. Schwartz LI, Twite M, Gulack B, Hill K, Kim S, Vener DF. The perioperative use of dexmedetomidine in pediatric patients with congenital heart disease: an analysis from the Congenital Cardiac Anesthesia Society-Society of Thoracic Surgeons Congenital Heart Disease database. Anesth Analg. 2016;123:715-21.

33. Holowachuk S, Zhang W, Gandhi SK, Anis AH, Potts JE, Harris KC. Cost savings analysis of early extubation following congenital heart surgery. Pediatr Cardiol. 2019;40:138-46.

34. Hickey PA, Connor JA, Cherian KM, et al. International quality improvement initiatives. Cardiol Young. 2017;27:S61-S68.

35. Richards M, Latham G, Ross F, Eisses M, Geiduschek J, Joffe D. To OTE or not to OTE: that is the question-current international trends of on the table extubation after pediatric cardiac surgery. J Cardiothorac Vasc Anesth. 2019;33:416-7.

Publisher's note Springer Nature remains neutral with regard to jurisdictional claims in published maps and institutional affiliations. 